\title{
O Programa Médico de Família de Niterói como Estratégia de Implementação de um Modelo de Atenção que Contemple os Princípios e Diretrizes do SUS
}

\author{
LUIZ CARLOS MOREIRA HÜBNER • \\ TÚLIO BATISTA FRANCO •
}

\section{RESUMO}

Este texto foi construído a partir da narrativa dos atores sociais envolvidos na gestão do Programa Médico de Família (PMF) de Niterói, que vivencia, desde 1992, sua concepção de modelo centrado na Estratégia de Saúde da Família, através de um desenho metodológico próprio, que difere em alguns aspectos da proposta do Ministério da Saúde. Tem o objetivo de revelar os modos de produção do cuidado com base nos processos desenvolvidos pelo PMF. Estes se referem ao processo de trabalho que envolve a equipe de base e uma equipe de supervisores técnicos; às práticas assistenciais centradas na concepção da produção social da saúde, referenciada no campo teórico da vigilância à saúde; e à produção de novos sujeitos históricos, profissional médico e população, com base em práticas de educação permanente, realizadas no próprio ambiente de trabalho e orientadas para a práxis, associada a processos de subjetivação disparados a partir do contato direto no ambiente social da população adscrita às equipes. A literatura que discute modelos tecnoassistenciais em saúde tem-se dedicado em grande medida ao estudo do Programa de Saúde da Família (PSF). Quanto ao PMF que foi inspiração para o próprio PSF, há pouca produção disponibilizada àqueles que buscam outros referenciais para modelos que trabalhem com a diretriz da vinculação de clientela a equipes assistenciais. Vale registrar que PMF e PSF, embora tenham inspiração na mesma matriz teórica da vigilância à saúde, na clínica do médico generalista e na diretriz central do vínculo, são na sua constituição e funcionamento diferentes, o que justifica estudos específicos de ambos os programas, ou estratégias de mudança do modo de produzir saúde.

Palavras-chave: Política de saúde; descentralização; saúde da família.

Recebido em: 30/08/2006.

Aprovado em: 08/02/2007. 


\section{Introdução: as origens da medicina de família}

Segundo Nogueira (1994), o Relatório Flexner serviu de referência para a modelagem da medicina americana: as recomendações contidas no relatório de 1910, auspiciado pela Fundação Carnegie, fixaram as linhas mestras em que se basearam as iniciativas posteriores de 'aperfeiçoar' a educação médica nos Estados Unidos, com reflexos mais ou menos poderosos em outras latitudes do continente: a) a necessidade de enlaçar o ensino com a investigação nas ciências biomédicas; b) a fundação do currículo das disciplinas clínico-cirúrgicas num hospital de referência.

Tal ideário de ensino se impôs ao resto do mundo no decorrer do século XX, operando, de um lado, a idéia de que a qualidade da formação em medicina é igual à capacidade de dominar e de aplicar corretamente os princípios das disciplinas biológicas e da clínica médica e, de outro, em relação à prática médica, propagando o conceito de que ela é proporcional ao tempo de contato que seus agentes tenham tido, e ainda tenham de alguma forma, com laboratórios das ciências biomédicas e com clínicas hospitalares bem equipadas.

Esta foi a base do modelo em que se pautou a lógica de organização dos serviços de saúde no Brasil, pelo menos até meados dos anos 80. A consolidação do modelo baseado em Flexner influenciou a formação médica em toda a América Latina, a partir da década de 40, através dos EUA, sendo ainda hoje hegemônico no país. Esse modelo, segundo SILVA JUNIOR (1998), entra em crise na década de 70, devido a problemas relativos à ineficiência, ineficácia e desigualdade na distribuição de seus progressos. Botazzo e Freitas (1998, p. 176) afirmam que:

\footnotetext{
"duas propostas de reformulação do ensino médico neste século devem ser destacadas pela sua enorme influência na organização dos serviços de saúde. São elas as de Abraham Flexner, em 1910, que influenciou na reforma das faculdades de medicina dos Estados Unidos e Canadá; e a de Bertrand Dawson, em 1920, que influenciou as faculdades da Inglaterra e da União das Repúblicas Socialistas Soviéticas (URSS), nos anos 40 e 50”.
}

A partir da Conferência Internacional de Alma Ata, em 1978, ganham força as idéias da Medicina Comunitária, também chamada de Cuidados Primários de Saúde, Medicina Simplificada etc. Bertrand Dawson fez, em 1920, a crítica do modelo flexneriano, e elaborou um relatório propondo a reestruturação dos serviços de saúde que seriam responsáveis por ações 
O Programa Médico de Família de Niterói como Estratégia de Implementação...

preventivas e terapêuticas. A separação entre medicina Preventiva e Curativa é criticada por Dawson. Ao contrário de Flexner, Dawson considerava que a formação médica não deveria se dar apenas nos hospitais de ensino especializado, pois o médico generalista deveria exercer funções junto ao indivíduo e à comunidade.

Os serviços para as famílias de uma região deveriam ter como base um centro primário de saúde, que oferecesse serviços de Medicina Curativa e Preventiva a cargo de médicos generalistas, de uma enfermagem eficiente, e que contasse com a colaboração de consultores e especialistas visitantes. Os centros primários de saúde deveriam estar relacionados a centros secundários de saúde, e estes a um hospital, inclusive os de ensino, para benefício dos pacientes e do próprio pessoal médico, que desta maneira poderia acompanhar todas as etapas de uma doença, familiarizar-se com o tratamento e perceber as necessidades do paciente após a volta ao lar (SILVA JUNIOR, 1998, p. 54).

O Plano Dawson não foi implementado imediatamente na Inglaterra, mas teve influência no sistema de saúde da Rússia, após a Revolução de 1917. Depois da Segunda Guerra Mundial, foi seguido pela URSS, e pela própria Inglaterra, no Serviço Nacional de Saúde, em 1948, a partir do Plano Beveridge. Dawson achava que os currículos das escolas médicas, em vez de se preocuparem excessivamente com a constituição de disciplinas de especialidades, deveriam concentrar seus esforços na formação de um profissional mais generalista, capaz de exercer sua prática em um sistema de saúde regionalizado.

O modelo proposto por Dawson passou a ser o centro do programa de saúde na Inglaterra, sendo depois levado a outros países, como Cuba, após a revolução socialista de 1959, e Canadá, no final dos anos 60. Estes países podem ser considerados berços de experiências de medicina familiar no mundo. Moysés (2002) afirma que, em 1963, a Organização Mundial da Saúde (OMS) já publicava um documento sobre a formação de médicos de família (Informes Técnicos $\mathrm{n}^{\circ}$ 257). Mas foi nos Estados Unidos, na década de 60, que a proposta de médico de família mais se expandiu. Em 1969, a medicina familiar foi ali reconhecida como especialidade médica. Na década de 70, o modelo foi difundido no Canadá, México e em alguns países europeus.

O mesmo autor lembra que a proposta americana muito se diferenciava do modelo inglês, o general practitioner. Enquanto este foi vinculado a um programa amplo de reformas sociais (Relatório Beveridge), que criou as bases para o National Health Service, a proposta americana representava uma volta 
ao passado, quando o médico liberal cuidava dos problemas de saúde de toda a família, embora somente fossem atendidas as famílias com capacidade de desembolso para remunerá-lo. O modelo americano "era uma reação saudosista contra a tendência à hospitalização, à complexidade tecnológica e à fragmentação do trabalho médico" (curiosamente, um efeito direto do projeto, americano por excelência, representado pelo Relatório Flexner).

Desenvolveu-se a partir dos anos 60 nos EUA a proposta da Medicina Comunitária, como alternativa aos altos custos dos serviços médicos, responsabilizados pela dificuldade de acesso, aos mesmos, de amplas camadas da população. "Foram implantados como parte da chamada 'guerra à pobreza', por agências governamentais e universidades. Esses programas baseavam-se na necessidade de 'integração' dos marginalizados da sociedade americana, na visão funcionalista da época". (SILVA JUNIOR apud FRANCO; MERHY, 2003, p. 74).

De acordo com Silva Junior (1998), a Medicina Comunitária se estrutura a partir dos campos de conhecimentos da epidemiologia e vigilância à saúde, valorizando, portanto, as ações coletivas de promoção e proteção à saúde, com referência a um determinado território. Quanto à estrutura, organizam o fluxo da atenção à saúde de forma hierarquizada, considerando como nível primário as ações de menor complexidade (sic) a serem realizadas nos locais mais próximos da comunidade. Propõe uma revisão da tecnologia utilizada na assistência à saúde, a inclusão de práticas alternativas, "acadêmicas e populares" de medicina, e reestrutura o trabalho, inserindo outros profissionais, não-médicos, na função assistencial.

Donnangelo diz que

os programas de Medicina Comunitária norte-americana [...] não incluíram tampouco qualquer inovação significativa no processo de trabalho que não se encontrasse já de forma mais marcada em outros tipos de estrutura de atenção médica (DONNANGELO, 1976, p. 86-91).

As propostas pautadas na "Medicina Comunitária" chegaram à América Latina, financiadas pela OPAS, e instituições filantrópicas como a W. F. K. Kellog, entre outras. Através de seminários patrocinados por organismos internacionais, estimulou-se nas Faculdades de Medicina a criação de espaços onde se pudesse demonstrar a correção da nova abordagem de formação médica: os Departamentos de Medicina Preventiva (DMP). 
O Programa Médico de Família de Niterói como Estratégia de Implementação...

A Medicina de Família é considerada como pertencente ao mesmo campo da Medicina Comunitária, ambas no âmbito das Ações Primárias em Saúde (APS). No entanto, a Medicina de Família traz uma diferença, que é o fato de ter como pressuposto o foco da atenção na família e seu espaço singular, que é o domicílio. Na Europa é regulamentada através de consensos estabelecidos pela Sociedade Européia de Clínica Geral/Medicina Familiar, a organização regional européia da Organização Mundial de Médicos de Família (WONCA). A WONCA Europa constitui a liderança acadêmica e científica, em representação da Medicina Geral e Familiar, em todo o continente. Ela considera que "a Medicina Geral e Familiar (Clínica Geral / Medicina Familiar) é uma disciplina acadêmica e científica, com os seus próprios conteúdos educacionais, investigação, base de evidência e actividade clínica; é uma especialidade clínica orientada para os cuidados primários" (WONCA/Europa, 2002, p. 6).

A implantação da medicina de família no Brasil foi controversa no início dos anos 90. A lembrança das primeiras experiências de saúde da família associadas ao preventivismo liberal americano e ao fato de as propostas de atenção primária na América Latina terem sido financiadas pelos "países centrais" talvez explique a resistência de setores do movimento sanitário latinoamericano à medicina de família.

O apoio da Organização Pan-Americana da Saúde (OPAS), e Fundações como a Kellogg ou a Ford, junto com programas de governo americano, como o Ponto Quatro e a Aliança para o Progresso, e mais ainda, a proximidade ideológica com o modelo liberal de prática médica, causaram uma crítica intensa à medicina de família, por parte dos setores de esquerda do movimento sanitário latino-americano (MOYSÉS, 2002, p. 138).

Ao pensarmos em saúde da família como possibilidade de reorganização da atenção à saúde, não estamos nos referindo à proposta americana e sua ideologia preventivista, ou à estratégia de mera diminuição de custos da Medicina Comunitária, mas sim a um programa amplo de reformas sociais, coerente com a construção de uma abordagem histórico-estrutural dos problemas de saúde, num processo de crítica à medicina preventiva e sua base filosófica, servindo de base para um sistema nacional de saúde que considere os princípios da cobertura universalizada, pública, intersetorial, algo adaptado à nossa cultura, e enquanto serviços de saúde, organizados nos moldes dos modelos de Cuba, Inglaterra, ou Canadá. 
O município de Niterói, tradicional reduto do Movimento Municipalista Brasileiro, foi buscar no modelo cubano, também em 1992, sua referência para implantação do modelo de medicina familiar. A proposta de Niterói, o Programa Médico de Família (PMF), acabou servindo de modelo para outros projetos de saúde da família, inicialmente no estado do Rio de Janeiro, e posteriormente para vários municípios de outros estados brasileiros. O Ministério da Saúde, quando adotou o Programa de Saúde da Família (PSF) como estratégia nacional de construção de um novo modelo de atenção, contou com a participação permanente da equipe coordenadora municipal de Niterói, entre outras.

A organização do processo de trabalho centrado na vigilância à saúde tem sua principal premissa no princípio da territorialidade, tal como pode ser ilustrado pela proposta de Sistemas Locais de Saúde (SILOS), descrita em Mendes (1994). Tal perspectiva pressupõe conhecer detalhadamente o território, não apenas como área de abrangência, mas enquanto território-processo, pois só assim há a oportunidade de definir problemas, um conjunto de prioridades e os recursos para atender às necessidades de saúde da comunidade, considerando cada situação específica. O território é compreendido como o espaço onde vivem grupos sociais, suas relações e condições de subsistência, trabalho, renda, habitação, acesso à educação (e o seu saber preexistente), como parte integrante do meio ambiente, possuidor de uma cultura, de concepções sobre saúde e doença, família, sociedade. A equipe precisa se inserir nesse território, estimulando a organização comunitária e junto com esta população buscar parcerias intersetoriais na perspectiva de melhores condições de vida e saúde. Estimular a participação popular como prática política, buscando permanentemente parcerias intersetoriais, faz parte da rotina do PMF de Niterói, sem desconsiderar a importância das dimensões de prevenção e assistência à saúde.

Um aspecto importante da organização do processo de trabalho diz respeito à diretriz do vínculo, isto é, a adscrição de clientela a determinada equipe de saúde, sendo esta responsável pelo cuidado àquela população, sugerido por Campos (1992, p. 133-213). Para Merhy e Chakkour (1997), o vínculo se refere também à responsabilização para com o usuário, o que fortalece a relação e o uso de tecnologias leves no processo de trabalho, conduzindo a maiores ganhos de autonomia do usuário para viver a vida. Camargo Junior. et al. (2006, p. 227), discutindo o tema, afirmam que o vínculo implica uma "mudança de paradigma, pois, ao implementar mudanças que resultem num novo processo de trabalho, tendo como foco o sujeito, a tendência é o resgate do espaço de trabalho como lugar de sujeitos". 
O Programa Médico de Família de Niterói como Estratégia de Implementação...

A Medicina Comunitária (ou Atenção Primária em Saúde), em sua lógica preventivista, critica a dicotomia entre Medicina Preventiva e Curativa. Ao contrário de Flexner, considera que a prática e a formação médica não deveriam se dar apenas nos hospitais especializados, pois o médico generalista deveria exercer funções tanto junto ao indivíduo quanto frente à comunidade. Resgata o objeto coletivo das práticas de saúde, mas o restringe aos limites da comunidade, sem considerar suas macrodeterminações. Esse pensamento incorpora em sua prática, além do controle de danos (medicina curativa) o controle de riscos atuais e potenciais (medicina preventiva), trabalhando a proteção à saúde e estabelecendo protocolos de investigação, através de uma oferta organizada de ações programáticas em saúde (puericultura, imunização, pré-natal, hipertensão, diabetes, etc.).

A Produção Social da Saúde (e sua concepção histórico-estrutural dos problemas de saúde) inova no objeto da sua prática, ao incorporar como conceito estratégico a determinação social e a historicidade do conceito de saúde-doença. Como conceitos estratégicos, adotaria a prática política e a consciência sanitária como parte da consciência social, buscando, a partir dessa prática, uma transformação social. Vai incorporar, além das dimensões controle de danos e controle de riscos, o controle de causas, trabalhando a partir de determinantes socioeconômicos, culturais e ambientais, procurando estimular uma intervenção social organizada (participação popular) na busca permanente de ações intersetoriais capazes de criar condições propícias para a promoção de saúde. Trabalha na perspectiva da promoção, mas sem perder de vista as dimensões controle de risco (prevenção) e controle de danos (medicina curativa).

\section{O Programa Médico de Família de Niterói}

Segundo Mascarenhas (2003), o município de Niterói vem-se destacando no cenário nacional por sua participação ativa nos processos de discussão em torno das inovações institucionais e das mudanças no modelo assistencial à saúde desde o final da década de 70, desenvolvendo propostas com esse fim, a partir de várias iniciativas como: 1) constituição da rede municipal de saúde, inspirada na estratégia de atenção primária preconizada pela OMS. A então Secretaria Municipal de Saúde e Promoção Social de Niterói (SMSPS) elaborou o Plano de Ação para o Setor Municipal (1977-80), que propunha a extensão de cobertura em bairros periféricos, até então não cobertos por serviços de saúde, a partir da implantação de uma rede básica de serviços e utilização 
de agentes de saúde, priorizando a atenção primária. 2) A implementação do projeto das Ações Integradas de Saúde (Projeto Niterói), no período 1982 a 1987, que se propunha a articular várias instituições prestadoras de serviços numa rede hierarquizada de atenção em nível local. Em 1989, uma coligação de partidos encabeçada pelo PDT elegeu o novo prefeito de Niterói, que convidou para o cargo de secretário municipal de Saúde, o até então secretário executivo do "Projeto Niterói" e profissional que militava ativamente no "movimento sanitário" local. Grande parte dos técnicos que exerciam funções nos grupos de trabalho desse projeto assumiu cargos na Secretaria Municipal de Saúde, promovendo o encaminhamento do processo de municipalização da saúde e a reorganização do sistema local, respaldados pelas recomendações da VIII Conferência Nacional de Saúde (1986) e pela Constituição Federal de 1988. Foi então criada a Fundação Municipal de Saúde de Niterói (FMSN), em 1989, para tentar agilizar um processo de reestruturação do sistema local de saúde. 3) Implementação do processo de municipalização e criação dos Distritos Sanitários, em 1989. 4) Implantação do Programa Médico de Família, a partir de 1992.

Assim Niterói vivencia, desde 1992, seu programa de saúde da família, na construção de um modelo de atenção que implemente os princípios e diretrizes do Sistema Único de Saúde (SUS). Como vimos, o grupo que participou da experiência docente-assistencial no município (o Projeto Niterói) assume a Secretaria de Saúde em 1989. Em 1991, o secretário municipal de Saúde visita Cuba para conhecer o modelo de medicina familiar e, na oportunidade, assina convênios de colaboração técnico-científica entre Cuba e Niterói. Um técnico designado pelo Ministério da Saúde de Cuba passa a assessorar permanentemente uma equipe multiprofissional designada pelo secretário para elaborar uma proposta adaptada de saúde da família para o município. Essa equipe visitou Cuba para conhecer o modelo, e após um ano de trabalho, elaborou um documento norteador do Programa Médico de Família de Niterói, que detalharemos a seguir.

A Fundação Municipal de Saúde de Niterói, segundo Vasconcellos (2002), concebeu sua proposta de saúde da família como uma estratégia de eqüidade, uma vez que ela se implantaria nas áreas de maior risco social e ambiental do município, privilegiando moradores com renda familiar mensal inferior a cinco salários mínimos. Depois de um ano de estudos preliminares, o município inaugurava, em setembro de 1992, seu primeiro serviço (Módulo do Programa Médico de Família). 
O Programa Médico de Família de Niterói como Estratégia de Implementação...

Vários estudos têm-se dedicado ao Programa Médico de Família de Niterói, entre eles o de Cohen (2002), que apresenta o PMF como uma alternativa urbana ao Programa Saúde da Família (PSF) do Ministério da Saúde. A autora analisa as dificuldades de integralidade da atenção no sistema de saúde no município, destacando os riscos inerentes ao fato de o PMF constituir uma experiência de flexibilização de gestão de serviços de saúde, onde já existe uma ampla rede instalada. Reflete, ainda, a coerência da metodologia introduzida pelo PSF e seu objetivo de (re)orientação do modelo assistencial, confrontando as propostas de abordagem familiar do Ministério da Saúde e de Niterói.

Senna e Cohen (2002) examinam o impacto produzido pela implantação da estratégia saúde da família na organização dos serviços locais, partindo do entendimento de que a adoção do PMF foi impulsionada pelo avanço do processo de descentralização setorial em curso no país. Discute a perspectiva de inauguração de um novo modelo assistencial com base em três temas centrais: a) a relação com o sistema local de saúde; b) a questão do controle social; e c) a gestão de recursos humanos em saúde. Entende-se que o modelo assistencial não é dado $a$ priori, mas construído no cotidiano das relações políticas entre atores sociais com graus diferenciados de incorporação de suas demandas pelo poder público, o que dá lugar a retraduções diversas do modelo proposto por esta política.

Mascarenhas e Almeida (2002) discutem o Programa Médico de Família em Niterói numa abordagem reflexiva sobre sua implantação e avaliação em cima dos resultados que se verificavam à época. Outra referência importante é a tese de doutorado de Mascarenhas (2003) apresentada à Escola Nacional de Saúde Pública (ENSP), que analisa a implementação da atenção básica em saúde no município de Niterói/RJ, através de estudos de caso de uma Unidade Básica de Saúde, no bairro de Santa Bárbara, e de um módulo do Programa Médico de Família, no bairro de Jurujuba, e conclui que há maior eficácia na unidade onde funciona o Médico de Família do que na Unidade Básica de Saúde, que ainda se organiza nos moldes tradicionais.

Houve também melhor desempenho do módulo do PMFN de Jurujuba em relação à UBS de Santa Bárbara, em termos de acolhimento e vínculo e responsabilização.

Embora os estudos de caso não permitam estabelecer relações de causaefeito entre os dois modelos assistenciais, os diferenciais observados fortalecem o pressuposto das relações entre processos de trabalho e qualidade da Atenção Básica em Saúde. Tal afirmação é corroborada pela percepção 
levantada dos profissionais e usuários das modalidades analisadas (MASCARENHAS, 2003, p. 152).

A partir dessas considerações, a autora faz uma minuciosa reflexão sobre o funcionamento do PMF, comparado a uma unidade de saúde tradicional, com foco no processo de trabalho e fluxos assistenciais, tendo como marcadores o acolhimento, vínculo e responsabilização em relação ao usuário.

\section{Procedimentos metodológicos do PMF/Niterói}

Para implantação do PMF, foram considerados alguns requisitos básicos como critérios, a saber:

1) bairros ou aglomerações populacionais de baixa renda, não contemplados pelo poder público local com equipamentos sociais;

2) estrutura geograficamente fechada, constituindo conjunto populacional definido, com perfil socioeconômico semelhante, com vistas à adscrição da clientela ao serviço. Tal requisito é algumas vezes questionado, pois pode sugerir, na consideração de clientela encerrada em fronteiras, contraposição ao princípio da universalidade. No caso de Niterói, segundo a Secretaria de Saúde local (VASCONCELLOS, 2002), não se trata de restringir acesso aos serviços, e sim ampliá-los, uma vez que nenhuma unidade de atenção primária teve suas portas fechadas para abrigar um módulo do PMF;

3) existência, na área, de organização comunitária com vínculos locais e perspectivas organizativas, que permitam co-gestão do modelo.

4) os profissionais de saúde são contratados pelas Associações de Moradores em regime de 40 horas de trabalho semanal, regidos pela CLT, através de repasse integral de recursos financeiros do poder público municipal às associações, que necessitam estar legalmente constituídas. Os profissionais do PMF (coordenadores, supervisores, médicos e auxiliares de enfermagem) são contratados através do contrato de co-gestão que se estabelece entre poder público e sociedade civil organizada.

5) os módulos (serviços de saúde do programa) são divididos em microáreas (setores). Cada setor abrange em média 1.200 pessoas. 
O Programa Médico de Família de Niterói como Estratégia de Implementação...

Um módulo deverá ter tantos setores quantos forem necessários para cobrir toda a população da área. A área geográfica de abrangência de cada setor deve permitir o acesso da equipe básica (médico e auxiliar) a todos os domicílios do setor, e das pessoas ao Módulo, sem o uso de meios de transporte.

6) todas as famílias do local deverão ser cadastradas (Cadastro Familiar). Somente depois de cadastrada e conhecido o perfil socioeconômico, ambiental, e as principais patologias referidas pela comunidade, é que se iniciam os trabalhos nos módulos. 7) As ações da equipe básica de saúde serão executadas no interior dos módulos, nas residências, na rede de referência de saúde do município, quando necessário, e/ ou nos equipamentos sociais da comunidade. Os profissionais deverão dividir sua carga horária entre os trabalhos de consultório (20h) e de campo (20h). Cada equipe fará agendamento prévio das famílias inscritas para atendimento ambulatorial e domiciliar, progressiva e continuamente, até que seu universo populacional seja todo abrangido.

Buscando equacionar o descompasso entre o perfil profissional existente hoje no mercado e o requerido pela nova lógica de modelo proposto pelo PMF, este trabalha com a concepção de Grupo Básico de Trabalho (GBT). Cada GBT é constituído por um coordenador, uma equipe de supervisores (composta por clínico geral, pediatra, ginecologista-obstetra, sanitarista, assistente social, enfermeiro e psiquiatra ou psicólogo), que darão apoio técnico e metodológico à equipe básica, que é constituída de médicos generalistas e auxiliares de enfermagem.

O coordenador representa o elo fundamental da equipe com as instâncias superiores da Secretaria de Saúde e demais órgãos relacionados ao programa. Aponta para a secretaria e/ou estabelece, por delegação, articulações interinstitucionais de interesse do programa. É responsável pelo controle metodológico, através do gerenciamento de atividades dos supervisores e equipe básica. Intermedeia a relação entre a equipe básica e as associações de moradores, desmonopolizando saberes acerca da metodologia do programa, contribuindo na co-gestão do trabalho. É também responsável pela reunião trimestral com o GBT para avaliação da metodologia.

O supervisor compõe a banca de seleção das equipes. Realiza treinamento em serviço. Cada módulo deverá ser visitado semanalmente por cada supervisor. Realiza interconsultas no consultório e/ou domicílio. Avalia o 
desempenho das equipes, através do acompanhamento da implementação dos protocolos de trabalho. Elabora e organiza o processo de educação continuada, através de treinamento semanal de rotina, onde as equipes deixam suas áreas de atuação para a participação no treinamento semanal. Operacionaliza a referência e contra-referência. Cada equipe de supervisão é responsável por até 20 equipes básicas (médico e auxiliar de enfermagem nos módulos).

Cabe destacar algumas adaptações feitas em relação ao modelo cubano, na construção do desenho metodológico do PMF de Niterói. Uma delas é a obrigatoriedade, em Cuba, de o médico de família e a enfermeira residirem no local onde se instala a unidade do Médico de Família (em Cuba, o médico e a enfermeira residem no segundo andar da unidade de saúde), o que no Brasil é sobremodo dificultado pelas precárias condições ambientais e de segurança das áreas onde se situam essas unidades, principalmente nos médios e grandes centros urbanos. Outra adaptação foi feita na criação da equipe de supervisão: em Cuba, os supervisores (que têm a mesma composição da equipe de Niterói) são docentes da faculdade de medicina que supervisionam os médicos de família nos módulos. Tal situação é facilitada pelo fato de, em Cuba, as faculdades de Medicina serem subordinadas ao Ministério da Saúde, e não ao Ministério da Educação, como no Brasil.

Segundo Vasconcelos (2002), quando da implementação do PMF em Niterói, em 1992, a idéia de se trabalhar com a figura de um médico generalista era absolutamente contra-hegemônica, o que dificultava ainda mais o estabelecimento de uma parceria institucional entre entidades do MEC (faculdades) e os serviços de saúde municipais. Niterói optou por selecionar de seus quadros os profissionais que comporiam as equipes de supervisão. Esses profissionais, na sua maioria, eram vinculados à universidade e aos serviços de saúde do município.

O médico de família deverá ter disponibilidade de trabalhar em horário integral (40 h/semana); compromisso social fundamentado na relação médicopaciente a ser avaliada pela população, e tecnicamente, pela equipe de supervisores; disposição para desenvolver trabalho integral e continuado dirigido à promoção de saúde em caráter preventivo e curativo, junto às famílias inscritas em seu setor, no ambulatório e nas residências; capacidade resolutiva para desempenho de atividades de outras áreas de conhecimento relativas às necessidades das famílias adscritas, como ações destinadas à educação em saúde, assistência e promoção social, junto com o auxiliar de enfermagem. Disponibilidade para participar de treinamentos e/ou reciclagens, promovidas 
O Programa Médico de Família de Niterói como Estratégia de Implementação...

pelos supervisores especialistas. Deverá ter residência médica em saúde pública, clínica médica ou pediatria preferencialmente, ou experiência comprovada em campo como generalista.

O auxiliar de enfermagem desenvolve todas as ações de auxiliar de enfermagem e de agente comunitário de saúde. Reside na área de implantação do programa. Deverá ter compromisso social fundamentado na relação profissional/usuário, a ser avaliado pela população e pela equipe técnica; disposição para desenvolver trabalho integral e continuado de promoção à saúde frente a todas as famílias cadastradas, no ambulatório e nas residências; ter concluído o curso de auxiliar ou técnico; disponibilidade de trabalhar em horário integral.

Cada módulo conta ainda com um auxiliar de limpeza e um vigia noturno, também morador da comunidade. Não existem funcionários com funções administrativas nos módulos, pois estas são executadas pela equipe básica.

As necessidades de referenciamento aos níveis de maior complexidade do sistema são em primeira instância discutidos com a equipe de supervisão, na busca de maior resolutividade possível no nível local. Cada módulo do PMF está vinculado a uma policlínica regional, que conta com especialidades que demandam menor aparato tecnológico, como cardiologia, dermatologia, endocrinologia, nutrição, odontologia etc. As demais especialidades médicas são referenciadas às policlínicas de especialidades. A coleta de material (sangue, fezes, urina) para exames complementares é feita nos módulos pelas auxiliares de enfermagem e encaminhadas pelo serviço ao laboratório de referência. Tal processo é agilizado por um veículo disponibilizado pelo PMF para cada grupo básico, que circula diariamente para atender às necessidades dos módulos. Assim como o material coletado para exames, os preventivos, as solicitações de consultas especializadas e exames são agilizadas por esse veículo, que traz ao Serviço de Atenção ao Usuário (SAU) as solicitações, que retornam aos módulos com dia e hora marcados. As solicitações de internação hospitalar são encaminhadas à Central de Regulação do município, que define a unidade hospitalar a ser encaminhado o usuário. O PMF conta com três ambulâncias para a remoção de pacientes. Conta, desde 2004, com a excelência do Serviço de Assistência Móvel de Urgência (SAMU), que tem agilizado sobremodo o acesso a emergências e internações hospitalares solicitadas pelo Programa.

O Programa Médico de Família de Niterói vai inovar enquanto modelo, em vários aspectos: o mais importante talvez seja a mudança total da lógica de 
organização do serviço, que deixa de trabalhar como mero receptor de demanda para se organizar em estratégias de busca ativa, de responsabilidade sanitária.

Outro aspecto importante da metodologia do PMF é o processo de cogestão estabelecido com as associações de moradores locais, e a vinculação permanente dos profissionais a uma população de no máximo 1.200 pessoas. Em universo maior, a nosso ver, é difícil de ser trabalhado na lógica da vigilância em saúde. Não podemos esquecer que esta população adscrita vive em condições consideradas de grande risco social e ambiental.

Os presidentes das associações de moradores passam à condição de co-gestores do programa. Os profissionais são selecionados pela equipe de supervisão e contratados por essas associações, que, através de um repasse do município, os remuneram mensalmente (contratos regidos pela CLT). Todos os recursos financeiros são contabilmente administrados pelo Departamento Financeiro do PMF, mas todas as despesas, inclusive de recursos humanos, são autorizadas pela associação co-gestora local. Essa estratégia, a nosso ver, representa uma experiência nova de controle social da gestão, embora a coordenação do programa faça questão de destacar que não é pela relação empregador/empregado que se dá o controle social do processo. São as reuniões de setor (equipes se reúnem a cada três meses com a população adscrita, para avaliar o processo de trabalho e discutir a metodologia), que se constituem no principal mecanismo de controle social do processo e ponta de lança na discussão sobre a necessidade de ações intersetoriais com a comunidade.

\section{Conclusões}

Em relação aos princípios do SUS, o PMF procura realizá-los buscando articular o saber da vigilância à saúde, a clínica exercida pela equipe de PMF e a equipe de supervisores, com os elementos que constituem uma certa rede social de proteção à saúde. Assim, a integralidade da ação é facilitada pela inserção das equipes no contexto de vida dos usuários, a partir do processo de cadastramento das famílias feito pelas mesmas e do trabalho de campo diário, que facilita a compreensão dos determinantes do processo saúde/doença. A equipe de supervisão do PMF atua como facilitadora tanto da maior resolutividade possível no nível local (através das interconsultas), como dando maior agilidade no agendamento das solicitações de referência aos níveis de maior complexidade do sistema - através do Serviço de Atenção ao Usuário (SAU), das Policlínicas Regionais e da Central de Regulação de Leitos do município). 
O Programa Médico de Família de Niterói como Estratégia de Implementação...

A participação popular se operacionaliza pelo controle social da gestão e se dá nas reuniões de setor, na participação das associações de moradores na gestão do programa através do contrato de co-gestão e nas reuniões comunitárias com enfoque na educação em saúde, considerando relevantes os saberes da própria comunidade no processo de gestão do PMF. $\mathrm{O}$ acesso e a eqüidade operam a partir de uma idéia geral de inclusão social, ampliação da porta de entrada ao sistema de saúde priorizando comunidades situadas em área de maior risco social e ambiental, atenuando níveis de exclusão social. A intersetorialidade se organiza a partir de uma articulação com segmentos interinstitucionais e sociedade civil organizada da área de abrangência das unidades, realizada pelas Policlínicas Regionais e Secretarias Regionais da Prefeitura de Niterói.

O PMF sofre adaptações da proposta cubana de organização da atenção básica, mesmo tendo importado de lá esse modelo. Contudo, as mudanças em relação à sua versão original são de ordem organizacional, permanecendo a identidade quanto aos aspectos de funcionamento e organização do processo de trabalho, principalmente.

Importante questão tratada pelo PMF diz respeito ao perfil do médico generalista, até então um profissional que não existe no mercado de trabalho da saúde. Procura-se equacionar o descompasso entre o perfil profissional existente e o requerido pelo PMF, através da instituição de um coordenador e uma equipe de supervisão permanente, constituída por especialistas nas clínicas básicas, um profissional de saúde coletiva, um assistente social, um profissional de saúde mental e um enfermeiro, que semanalmente visitam todas as unidades do PMF e têm a função de supervisão técnica e orientação do trabalho dos médicos do PMF. Isto, por um lado, cria um intercâmbio de experiências e opera um processo educativo, que prioriza a transferência de conhecimento, discussão de casos e interconsultas, criando uma prática de educação permanente no âmbito do PMF - isto é, uma educação no e para o trabalho. Por outro lado, os médicos do PMF devem obrigatoriamente realizar visitas domiciliares diárias aos seus usuários no território, executando tarefas que são específicas do médico, ou seja, consultas nos domicílios, tratando os processos mórbidos, e também realizam outras atividades, como atualização cadastral, busca ativa de casos e diagnóstico situacional da sua clientela. Com essa vivência da realidade social na qual se produz o processo saúde-doença, pretende-se que o médico seja impactado no seu modo de conceber o mundo da saúde, ressignificando seus valores e cultura 
em relação às práticas assistenciais. Isso também é parte do método do PMF de formação de um novo profissional médico para o atendimento à população usuário do SUS.

A idéia que se articula é a de produção de um novo modelo assistencial e, ao mesmo tempo, um novo sujeito histórico, profissional médico de perfil diferente do que usualmente tem sido formado pela maioria das escolas médicas. O contato com a realidade experimentada e vivida por cada um fala por si mesmo aos próprios médicos que se lançam à atividade de visitas domiciliares em contato com sua clientela no seu próprio local de moradia.

São identificados como maiores entraves para uma melhor operacionalização do SUS de Niterói, dentre outros, a consolidação de um sistema de informação ágil, que facilite a avaliação do processo de trabalho, e o impacto das ações no nível local, além de uma melhor regulação da rede de serviços de nível secundário, público e privados contratados pelo município. Segundo Vasconcellos (2002), a informatização dos serviços ligados a uma rede central encontra-se em implantação no município.

O conceito de saúde adotado pelo PMF compreende a imprescindibilidade de articulações intersetoriais, de efetiva participação da sociedade, na busca de "um novo marco civilizatório". Tal processo certamente só se consolidará em municípios que encaram a reestruturação do Sistema Local de Saúde como política de governo, apoios institucionais combinados a processos de subjetivação que sejam capazes de criar um novo sujeito, protagonista da mudança dos serviços de saúde.

\section{Referências}

BOTAZZO, C.; FREITAS, S. F. T. (Org.). Ciências sociais e saúde bucal: questões e perspectivas. 1. ed. São Paulo: Editora da UNESP, 1998.

CAMARGO JUNIOR, Kenneth R. et al. Aspectos metodológicos da avaliação na atenção básica. In: PINHEIRO, R.; MATTOS, R. A. (Org.). Gestão em redes: práticas de avaliação, formação e participação na saúde. Rio de Janeiro: CEPESC, 2006. p. 223-241.

CAMPOS, G. W. S. Reforma da reforma: repensando a saúde. São Paulo: Hucitec, 1992. 
O Programa Médico de Família de Niterói como Estratégia de Implementação...

COHEN, M. M. Programa Médico de Família de Niterói (RJ): uma alternativa urbana do Programa Saúde da Família. Saúde em Debate, Londrina, v. 26, n. 61, p. 186-197, mai-ago 2002.

DONNANGELO, M. C. Saúde e sociedade. São Paulo: Duas Cidades, 1976.

ESCOREL, S. M. Reviravolta na saúde: origem e articulação do Movimento Sanitário. Dissertação (Mestrado em Saúde Pública) - Escola Nacional de Saúde Pública da FIOCRUZ, Rio de Janeiro, 1987.

FRANCO, T. B.; MERHY E. E. Programa Saúde da Família (PSF): contradições de um programa destinado à mudança do modelo tecnoassistencial. In: MERHY, E. E. et al. O trabalho em saúde: olhando e experienciando o SUS no cotidiano. São Paulo: Hucitec, 2003, p. 55-124.

FUNDAÇÃO MUNICIPAL DE SAÚDE DE NITERÓI. Implantação do Programa Médico de Família de Niterói. Relato de experiência. Niterói: FMS, 1993.

MASCARENHAS, M.; ALMEIDA, C. M. O Programa Médico de Família de Niterói (PMFN): uma agenda para reflexão. Saúde em Debate, Rio de Janeiro, v. 26, n. 60, p. $82-102,2002$.

MASCARENHAS, M. T. M. Avaliando a implementação da atenção básica no município de Niterói (RJ). Tese (Doutorado em Saúde Pública) - Escola Nacional de Saúde Pública da FIOCRUZ, Rio de Janeiro, 2003.

MENDES, E. V. (Org.). Uma agenda para a saúde. São Paulo. Hucitec, 1999. . (Org.). Distrito Sanitário: o processo social de mudança das práticas sanitárias do Sistema Único de Saúde. São Paulo: Hucitec, 1994.

MERHY, E. E.; CHAKKOUR, M. et al. Em busca de ferramentas analisadoras das tecnologias em saúde: a informação e o dia-a-dia de um serviço, interrogando e gerindo trabalho em saúde. In: MERHY, E. E.; ONOCKO, R. (Org.) Agir em saúde: um desafio para o público. São Paulo: Hucitec, 1997. p. 113 - 160.

MOYSÉS, S. J. (Org.). Os dizeres da boca em Curitiba: boca maldita, boqueirão, bocas saudáveis. Rio de Janeiro: CEBES, 2002.

NOGUEIRA, R. P. Perspectivas da qualidade em saúde. Rio de Janeiro: Qualitymark, 1994. 
ORGANIZAÇÃO MUNDIAL DE SAÚDE / UNICEF. Cuidados primários na saúde. Conferência de Alma-Ata, 1978.

PAIM, J. S. A Reforma Sanitária e os modelos assistenciais. In: ROUQUAYROL, M. Z. (Org.). Epidemiologia e saúde. Rio de Janeiro: MEDSI, 1994. p. 473-487.

SENNA, M. C. M.; COHEN, M. M. Modelo assistencial e estratégia saúde da família no nível local: análise de uma experiência. Ciência e Saúde Coletiva, v. 7, n. 3, p. 523-535, 2002.

SILVA JUNIOR, A. G. Modelos tecnoassistenciais em saúde: o debate no campo da saúde coletiva. São Paulo: Hucitec, 1998.

VASCONCELLOS, M. C. Entrevista concedida ao autor pela Vice-Presidente de Atenção Coletiva, Ambulatorial e da Família da Fundação Municipal de Saúde de Niterói. Niterói, RJ, 2002.

WONCA/OMS. A Definição Européia de Medicina Geral e Familiar. Wonca Europa, Barcelona, Espanha, 2002.

\section{NOTAS}

- Odontólogo, sanitarista, mestre em Odontologia Social pela UFF, professor no Instituto de Saúde da Comunidade da UFF; coordenador de área do Programa Médico de Família de Niterói. Endereço eletrônico: luizhubner@uol.com.br.

- Psicólogo, sanitarista, doutor em Saúde Coletiva; professor no Instituto de Saúde da Comunidade da UFF, pesquisador do CNPq. Endereço eletrônico: tuliofranco@vm.uff.br. 
O Programa Médico de Família de Niterói como Estratégia de Implementação...

\section{ABSTRACT}

\section{Niteroi's Family Doctor Program as a Strategy to Implement a Care Model that Addresses SUS's Principles and Guidelines}

This text is based on the narrative of social actors involved in the management of Niteroi's Family Doctor Program (FDP), whose idea of a family health strategy-centered model appeared in 1992, through its own methodology design, which differs, in some aspects, from the Health Ministry's proposal. It aims at revealing care production modes based on the processes developed by FDP. These refer to the work process which involves the basic team and a team of technical supervisors; care practices centered on health social production conception, setting the surveillance theoretical field as its reference; and the production of new historical subjects, medical professional, and population, based on permanent education practices, performed in the very work environment and oriented to praxis, associated to subjectivation processes triggered by direct contact in the social environment of each population assigned to the teams. Literature on health techno-care models has devoted itself largely to the study of Family Health Program (FHP). As for FDP, which was an inspiration for FHP, there is little production available to those who seek other references to the models working with the guideline of linking the clientele to care teams. It is worth recording that FDP and FHP, though inspired in the same surveillance theoretical matrix, in the practice of the GP and on the central guideline of the bond, are different in their constitution and functioning, which explains specific studies of both programs, or change strategies for health producing mode.

Key words: Health policy; decentralization; family health. 